\title{
Lumped damage mechanics as a diagnosis tool of reinforced concrete structures in service: case studies of a former bridge arch and a balcony slab
}

\author{
Rafael Nunes da Cunha \\ Federal University of Alagoas, Maceió, Brazil \\ rafael.cunba@ctec.ufal.br,.bttp://orcid.org/0000-0003-2503-6758 \\ Camila de Sousa Vieira \\ Laboratory of Mathematical Modelling in Civil Engineering, Federal University of Sergipe, São Cristóvão, Brazil \\ milavieira@gmail.com, bttp://orcid.org/0000-0002-5371-191X \\ David Leonardo Nascimento de Figueiredo Amorim \\ Laboratory of Mathematical Modelling in Civil Engineering, Federal University of Sergipe, São Cristóvão, Brazil \\ Federal University of Alagoas, Maceió, Brazil \\ davidnf@academico.ufs.br, bttp:/ /orcid.org/0000-0002-9233-3114
}

\begin{abstract}
Reinforced concrete structures may need repair in order to ensure the designed durability. The assessment of the structural condition usually is made in loco, but sometimes numerical analyses are required as a low cost and effective preliminary diagnosis. Lumped damage mechanics (LDM) may be used as an alternative diagnosis procedure. In LDM approaches for reinforced concrete structures, the concrete cracking in modelled by a damage variable and the reinforcement yielding is represented by plastic deformations. Therefore, this paper presents LDM as a diagnosis tool to analyse actual structures. Then, the procedure is applied in two case studies. The first one is a former bridge arch tested in laboratory. Such bridge was deactivated after almost three decades in service and some damage were observable. The second case study deals with a reinforced concrete balcony that collapsed after fifteen years of service. In the moment of collapse, only the dead load was acting in the balcony. The results show that LDM numerical response of those structures are quite close to laboratory observations, for the former bridge arch, and to in loco measurements, for the balcony. In this sense, according to the analysed structures, LDM may be used as a diagnosis tool.
\end{abstract}

KEYwORDS. Lumped damage mechanics; Reinforced concrete; Diagnosis; Bridge arch; Balcony.

\section{open Access}

Citation: Cunha, R. N., Vieira, C. S., Amorim, D. L. N. F., Lumped damage mechanics as a diagnosis tool of reinforced concrete structures in service: case studies of a former bridge arch and a balcony slab, Frattura ed Integrità Strutturale, 58 (2021) 21-32.

Received: 29.04.2021 Accepted: 03.07.2021 Published: 01.10.2021

Copyright: (C) 2021 This is an open access article under the terms of the CC-BY 4.0, which permits unrestricted use, distribution, and reproduction in any medium, provided the original author and source are credited. 


\section{INTRODUCTION}

$\mathrm{R}$ einforced concrete $(\mathrm{RC})$ structures require periodical inspection, maintenance and repairs to ensure the designed durability. Inspections can identify damages that, if were not corrected, can lead to partial or total collapse of the structure. When a structure shows signs of damage it is necessary to investigate its causes, which results in a diagnosis that serves as the basis for adopting intervention measures.

The assessment of structural damage may occur in loco using non-destructive methods such as visual inspection [1], acoustic emission [2] and ground penetrating radar [3], or destructive methods as explosions [4]. This analysis can also take place in laboratory, using samples of an original structure [5] or with the combination of experimental and numerical analysis, aiming to reproduce the experimental behaviour, as the stress/strain and fatigue [6] or the damage and dynamic properties [7]. Other diagnosis techniques are based only on numerical analysis of the structures such as nonlinear dynamic analysis [8] or on artificial neural networks [9]. One of the most used computational method for modelling the occurrence of damage and monitoring the cracking process in reinforced concrete structures is the finite element method (FEM) [10-17]. However, a disadvantage of these procedures using FEM is the significant computational cost.

An efficient alternative to such procedures in order to assess damage in reinforced concrete structures is the Lumped Damage Mechanics (LDM). This theory combines the concepts of the classic damage and fracture mechanics in plastic hinges, which defines the concrete cracking as the damage variable. LDM was firstly proposed to analyse RC structures submitted to seismic loads [18-22]. Later, LDM was expanded for several other conditions, as impact loads [23-25] and tunnel linings [26-28].

One of the great advantages of using LDM to evaluate damage of reinforced concrete structures is the use of parameters easily obtained by civil engineers in practice, such as cracking moment and the load conditions. In order to ensure that LDM may be applied in actual engineering problems, Flórez-López et al. [29] defined structure integrity according to the damage level of the structural elements. For reinforced concrete elements, a damage value around 0.3 or 0.4 represents the beginning of the reinforcement yield, and a damage of approximately 0.6 means the bearing capacity of the element [29].

In the light of the foregoing, the objective of this paper is the application of LDM as a diagnosis tool of RC structures, using a former bridge arch and a balcony that suffered collapse as case studies. The first case is an arch that was removed from an actual bridge in China [13] and tested in laboratory and the second one is a collapsed balcony of an actual building in Brazil [30]. Then, the damage variable is used as a diagnosis tool, presenting satisfactory results for both analysed structures.

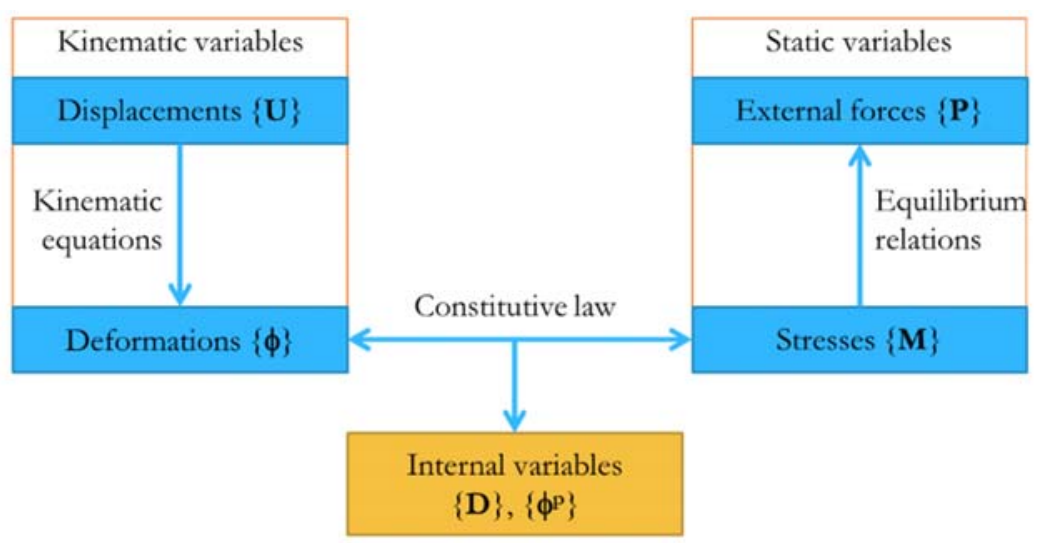

Figure 1: Relations among variables in a structural problem.

\section{REVIEW ON LUMPED DAMAGE MECHANICS FOR FRAMES AND ARCHES [26-29]}

he variables of a structural problem can be categorised in three sets: kinematic, static and internal ones (Fig 1). Such variables are related by three sets of equations, which can be called as kinematic equations, equilibrium relations and constitutive law (Fig 1). Classic finite element analysis usually relates directly the matrix of generalised displacements $\{\mathbf{U}\}$ and matrix of generalised external forces $\{\mathbf{P}\}$. Note that the approach presented in this paper presents more matrices, defined in this section. Then, considering a structure composed by frame and arch elements in a XZ Cartesian reference [26], such quantities are described by: 


$$
\begin{aligned}
& \{\mathbf{U}\}=\left\{\begin{array}{lllllllllllllll}
u_{1} & w_{1} & \theta_{1} & \ldots & u_{i} & w_{i} & \theta_{i} & \ldots & u_{j} & w_{j} & \theta_{j} & \ldots & u_{n} & w_{n} & \theta_{n}
\end{array}\right\}^{T} \\
& \{\mathbf{P}\}=\left\{\begin{array}{lllllllllllllll}
P_{u 1} & P_{w 1} & P_{\theta 1} & \ldots & P_{u i} & P_{w i} & P_{\theta i} & \ldots & P_{u j} & P_{w j} & P_{\theta j} & \ldots & P_{u n} & P_{w n} & P_{\theta n}
\end{array}\right\}^{T}
\end{aligned}
$$

where $u_{1}$ is the node 1 displacement parallel to the $\mathrm{X}$-axis, $w_{1}$ is the node 1 displacement parallel to the Z-axis and $\theta_{1}$ is the node 1 rotation on the $\mathrm{XZ}$ plane. Analogously, $P_{u n}$ is the applied force on node $n$ parallel to the $\mathrm{X}$-axis, $P_{w n}$ is the applied force on node $n$ parallel to the $\mathrm{Z}$-axis and $P_{\theta n}$ is the applied moment on node $n$ on the $\mathrm{XZ}$ plane.

The structural equilibrium is given by:

$$
\{\mathbf{P}\}=\sum_{b=1}^{m}[\mathbf{B}]_{b}^{T}\{\mathbf{M}\}_{b}
$$

being $[\mathbf{B}]_{b}$ the transformation matrix and $\{\mathbf{M}\}_{b}$ the generalised stresses of a finite element $\mathrm{b}$, both given as follows:

$$
\{\mathbf{M}\}_{b}=\left\{M_{i} \quad M_{j} \quad N_{i}\right\}^{T}
$$

Frame element:

$$
[\mathbf{B}]_{b}=\left[\begin{array}{ccccccccccccccc}
0 & 0 & 0 & \ldots & \frac{\sin \alpha_{b}}{L_{b}} & -\frac{\cos \alpha_{b}}{L_{b}} & 1 & \ldots & -\frac{\sin \alpha_{b}}{L_{b}} & \frac{\cos \alpha_{b}}{L_{b}} & 0 & \ldots & 0 & 0 & 0 \\
0 & 0 & 0 & \ldots & \frac{\sin \alpha_{b}}{L_{b}} & -\frac{\cos \alpha_{b}}{L_{b}} & 0 & \ldots & -\frac{\sin \alpha_{b}}{L_{b}} & \frac{\cos \alpha_{b}}{L_{b}} & 1 & \ldots & 0 & 0 & 0 \\
0 & 0 & 0 & \ldots & -\cos \alpha_{b} & \sin \alpha_{b} & 0 & \ldots & \cos \alpha_{b} & \sin \alpha_{b} & 0 & \ldots & 0 & 0 & 0
\end{array}\right]
$$

Arch element:

$$
\begin{aligned}
& \text { node } 1 \quad \text { node } i
\end{aligned}
$$

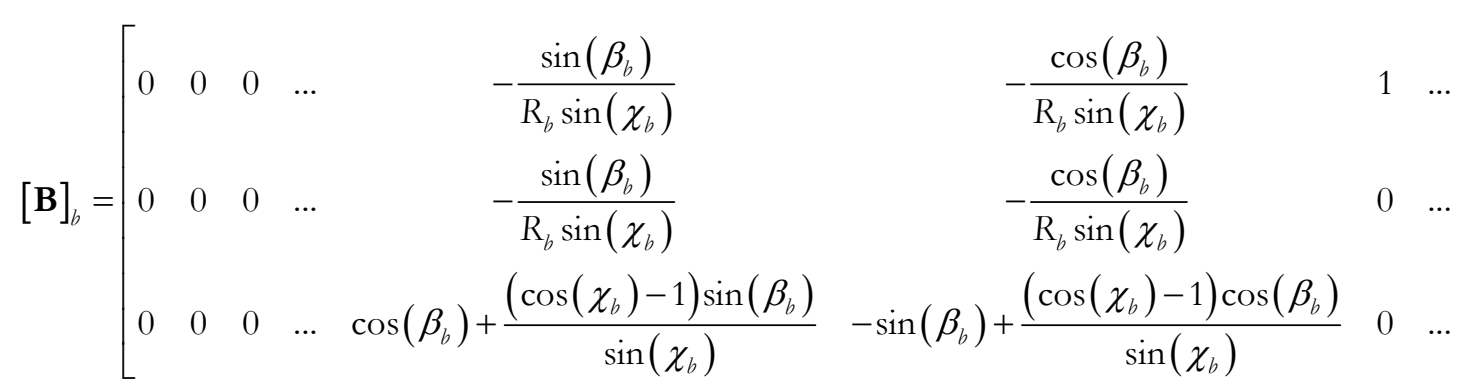

$$
\begin{aligned}
& \ldots \quad-\frac{\cos \left(\beta_{b}+\chi_{b}\right)}{R_{b}}+\frac{\cos \left(\chi_{b}\right) \sin \left(\beta_{b}+\chi_{b}\right)}{R_{b} \sin \left(\chi_{b}\right)} \quad \frac{\sin \left(\beta_{b}+\chi_{b}\right)}{R_{b}}+\frac{\cos \left(\chi_{b}\right) \cos \left(\beta_{b}+\chi_{b}\right)}{R_{b} \sin \left(\chi_{b}\right)} \quad \begin{array}{llllll}
0 & \ldots & 0 & 0 & 0
\end{array} \\
& \ldots \quad-\frac{\cos \left(\beta_{b}+\chi_{b}\right)}{\mathrm{R}_{b}}+\frac{\cos \left(\chi_{b}\right) \sin \left(\beta_{b}+\chi_{b}\right)}{\mathrm{R}_{b} \sin \left(\chi_{b}\right)} \quad \frac{\sin \left(\beta_{b}+\chi_{b}\right)}{\mathrm{R}_{b}}+\frac{\cos \left(\chi_{b}\right) \cos \left(\beta_{b}+\chi_{b}\right)}{\mathrm{R}_{b} \sin \left(\chi_{b}\right)} \quad \begin{array}{llllll}
1 & \ldots & 0 & 0 & 0
\end{array}
\end{aligned}
$$

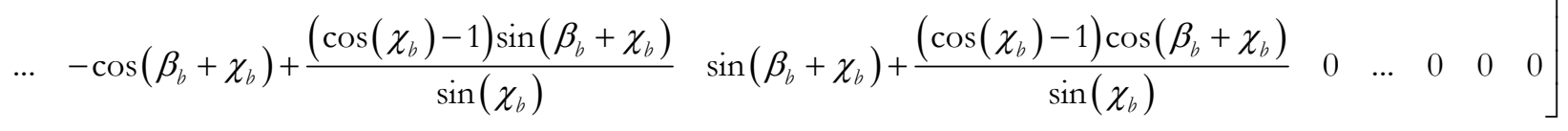

$$
\begin{aligned}
& \text { node } j \quad \text { node } n
\end{aligned}
$$


where $M_{i}$ and $M_{j}$ are bending moments on the nodes $i$ and $j$ of the element, respectively, $N_{i}$ is the axial force on the node $i$ of the element, $\alpha_{b}$ is the orientation of the frame element and $L_{b}$ its length; $\beta_{b}, \chi_{b}$ and $\mathrm{R}_{b}$ geometrically define the circular arch element (Fig 2). Note that the second member of (3) is the sum of the internal forces of each finite element.

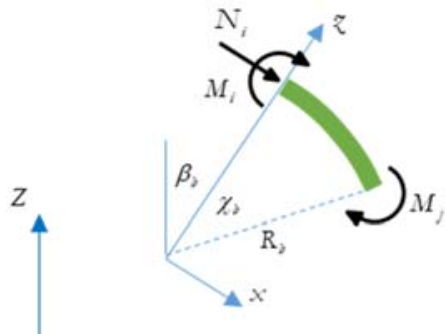

(a)

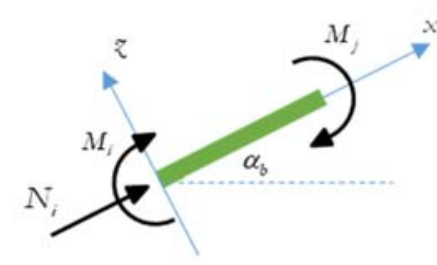

(b)

Figure 2: Generalised stresses and geometric definition of (a) arch and (b) frame finite elements.

The kinematic relations for a finite element are given by:

$$
\{\dot{\boldsymbol{\Phi}}\}_{b}=[\mathbf{B}(\mathbf{U})]_{b}\{\dot{\mathbf{U}}\}
$$

being $[\mathbf{B}(\mathbf{U})]_{b}$ the same transformation matrix previously presented in (5-6) considering large displacements and $\{\boldsymbol{\Phi}\}$ the matrix of generalised deformations, which is conjugated to $\{\mathbf{M}\}$ and written as:

$$
\{\boldsymbol{\Phi}\}_{b}=\left\{\begin{array}{lll}
\phi_{i} & \phi_{j} & \delta_{i}
\end{array}\right\}^{T}
$$

where $\varphi_{i}$ and $\varphi_{j}$ are flexural rotations due to the bending moments $M_{i}$ and $M_{j}$, respectively, and $\delta_{i}$ is the axial deformation related to $N_{i}$.

If small displacements and small deformations are assumed, (7) can be rewritten as follows:

$$
\{\boldsymbol{\Phi}\}_{b}=\left[\mathbf{B}_{0}\right]_{b}\{\mathbf{U}\}
$$

being $\left[\mathbf{B}_{0}\right]$ the transformation matrix for the initial condition.

The elastic relations of the element are obtained by assuming the deformation equivalence hypothesis, by applying the Castigliano's Theorem [26-27, 29] and considering the inelastic phenomena are concentrated at hinges located at the edges of the element (Fig 3):

$$
\left\{\boldsymbol{\Phi}-\boldsymbol{\Phi}^{p}\right\}_{b}=[\mathbf{F}(\mathbf{D})]_{b}\{\mathbf{M}\}_{b}
$$

where $\{\boldsymbol{\Phi}\}_{b}$ is the matrix of generalised plastic deformations, that accounts for reinforcement yielding, and $[\mathbf{F}(\mathbf{D})]_{b}$ is the damaged flexibility matrix, both written as:

$$
\begin{aligned}
& \left\{\boldsymbol{\Phi}^{p}\right\}_{b}=\left\{\begin{array}{lll}
\phi_{i}^{p} & \phi_{j}^{p} & 0
\end{array}\right\}^{T} \\
& {[\mathbf{F}(\mathbf{D})]_{b}=\left[\begin{array}{ccc}
\frac{1}{1-d_{i}} F_{11}^{0} & F_{12}^{0} & F_{13}^{0} \\
F_{12}^{0} & \frac{1}{1-d_{j}} F_{22}^{0} & F_{23}^{0} \\
F_{13}^{0} & F_{23}^{0} & F_{33}^{0}
\end{array}\right]}
\end{aligned}
$$


being $d_{i}$ and $d_{j}$ the damage variables at hinges $i$ and $j$, respectively, which account for concrete cracking. The terms $F_{i j}{ }^{0}$ are described in the Appendix for frame and arch elements.

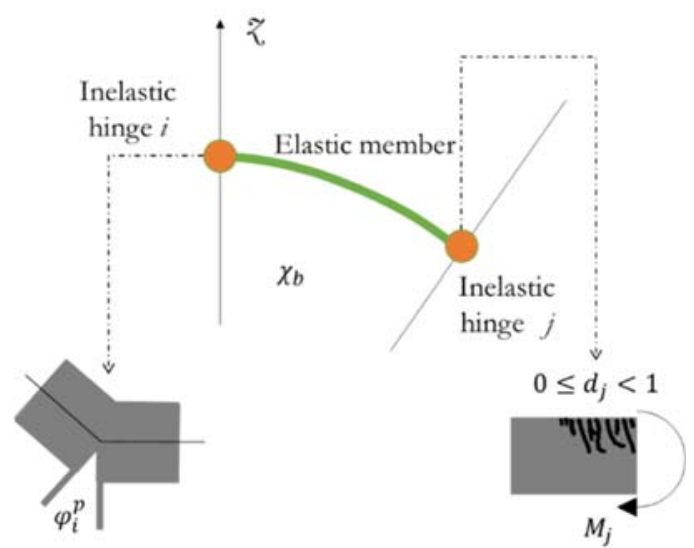

Figure 3: Lumped damage modelling for reinforced concrete members [26-29].

In order to complete the constitutive law, the evolution laws of internal variables (damage and plastic rotation) must be considered. Thus, consider the complementary energy of the finite element:

$$
W=\frac{1}{2}\{\mathbf{M}\}_{b}^{T}\left\{\boldsymbol{\Phi}-\boldsymbol{\Phi}^{p}\right\}_{b}
$$

The evolution law of the damage variables are obtained throughout the Griffith criterion i.e.

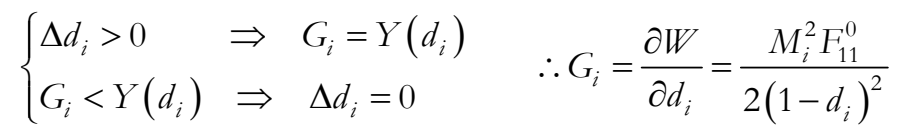

$$
\begin{aligned}
& \left\{\begin{array}{l}
\Delta d_{j}>0 \quad \Rightarrow \quad G_{j}=Y\left(d_{j}\right) \\
G_{j}<Y\left(d_{j}\right) \Rightarrow \Delta d_{j}=0
\end{array} \quad \therefore G_{j}=\frac{\partial W}{\partial d_{j}}=\frac{M_{j}^{2} F_{22}^{0}}{2\left(1-d_{j}\right)^{2}}\right.
\end{aligned}
$$

where $G_{i}$ and $G_{j}$ are the damage driving moments for the hinges $i$ and $j$, respectively, and $Y\left(d_{i}\right)$ and $Y\left(d_{j}\right)$ are the cracking resistance functions [28].

The cracking resistance function for reinforced concrete elements [29] is given by:

$$
Y\left(d_{i}\right)=Y_{0}+q \frac{\ln \left(1-d_{i}\right)}{1-d_{i}}
$$

being $Y_{0}$ and $q$ model parameters.

The plastic evolution laws for each hinge of the element are given by:

$$
\begin{aligned}
& \left\{\begin{array}{lll}
\Delta \phi_{i}^{p}>0 & \Rightarrow f_{i}=0 & \therefore f_{i}=\left|\frac{M_{i}}{1-d_{i}}-C \phi_{i}^{p}\right|-k_{0} \leq 0 \\
f_{i}<0 & \Rightarrow \Delta \phi_{i}^{p}=0 & \therefore f_{j}=\left|\frac{M_{j}}{1-d_{j}}-C \phi_{j}^{p}\right|-k_{0} \leq 0
\end{array}\right. \\
& \left\{\begin{array}{lll}
\Delta \phi_{j}^{p}>0 & \Rightarrow f_{j}=0 & \Rightarrow \Delta \phi_{j}^{p}=0
\end{array}\right.
\end{aligned}
$$


being $f_{i}$ and $f_{j}$ the yield functions for the hinges $i$ and $j$, respectively, and $C$ and $k_{0}$ model parameters. Note that the model parameters $Y_{0}, q, C$ and $k_{0}$ can be directly related to the classic theory of reinforced concrete structures, as presented by $[20,27-29]$.

\section{Case STUdies}

\section{Bridge Concrete Arch [13]}

7 he first case study is the failure analysis of two reinforced concrete arch ribs that were part of a 28 years old bridge in China. The geometry of the arches is described in Tab. 1. The failure experiments were made in laboratory where the arches were submitted to static loads [13]. Fig. 4 presents the location of the applied loads (P).

\begin{tabular}{cccccc}
\hline Span $(L)$ & Height $(H)$ & Radius & $\begin{array}{c}\text { Inclined angle at arch } \\
\text { foot }\end{array}$ & $\begin{array}{c}\text { Cross section } \\
\text { width }(T)\end{array}$ & $\begin{array}{c}\text { Cross section } \\
\text { height }(b)\end{array}$ \\
$19.72 \mathrm{~m}$ & $3.08 \mathrm{~m}$ & $17.89 \mathrm{~m}$ & $35.5^{\circ}$ & $20 \mathrm{~cm}$ & $28 \mathrm{~cm}$ \\
\hline
\end{tabular}

Table 1: Arch geometric parameters [13].

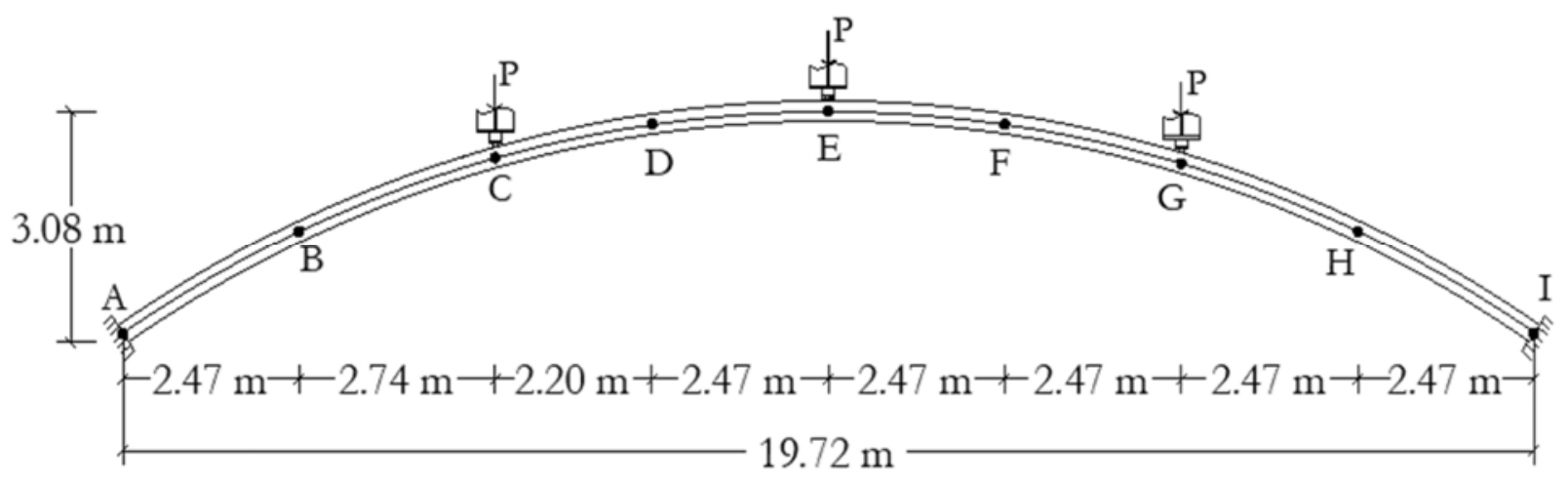

Figure 4: Lumped damage modelling for the arch tested by [13].

The loads were applied at middle (point E), at the left quarter plus $27 \mathrm{~cm}$ (point $\mathrm{C}$ ) and at the right quarter of the arch (point $\mathrm{G})$, which were applied in eighteen load steps. The two end sections of the arches were fixed.

The reinforcement is located near the upper and lower sides of the arch cross section. Three bars with $16 \mathrm{~mm}$ of diameter composed each layer. Tab. 2 presents the elastic constants of the materials.

\begin{tabular}{ccc}
\hline Material & Concrete & Steel \\
Elastic modulus E $(\mathrm{GPa})$ & 9.8 & 210 \\
Poisson's ratio $v$ & 0.17 & 0.27 \\
\hline
\end{tabular}

Table 2: Material elastic constants [13].

Due the long usage time and problems related to the removal and transportation of the arches, both of them suffered damages at the two ends (nodes A and I). Moreover, at $1 / 8$ distance of the left and right supports (nodes $\mathrm{B}$ and $\mathrm{H}$ ) the arches were also damaged, when they were being dismantling in the field, resulting in two notches.

It was obtained that the collapse load $\left(\mathrm{P}_{\max }\right)$ was equal to $68 \mathrm{kN}$ and $65 \mathrm{kN}$ for the tested arches. Tab. 3 presents the experimental data of the vertical displacements at the measured location, for different load ratios. 


\begin{tabular}{cc}
\hline \multirow{2}{*}{ Load $P / P_{\max }(\%)$} & Vertical displacement $(\mathrm{mm})$ \\
\cline { 2 - 2 } 0 & Node E \\
6.76 & - \\
8.46 & - \\
10.15 & 4.43 \\
11.84 & 5.02 \\
13.53 & 5.77 \\
16.91 & 7.24 \\
27.99 & 12.63 \\
39.06 & 17.39 \\
47.91 & 22.35 \\
52.35 & 24.96 \\
54.57 & 26.53 \\
59.41 & 30.07 \\
68.97 & 36.4 \\
73.09 & 39.49 \\
77.5 & 43.45 \\
90.88 & 56.43 \\
\hline
\end{tabular}

Table 3: Experimental data of vertical displacements for $P_{\max }=68 \mathrm{kN}$ [13].

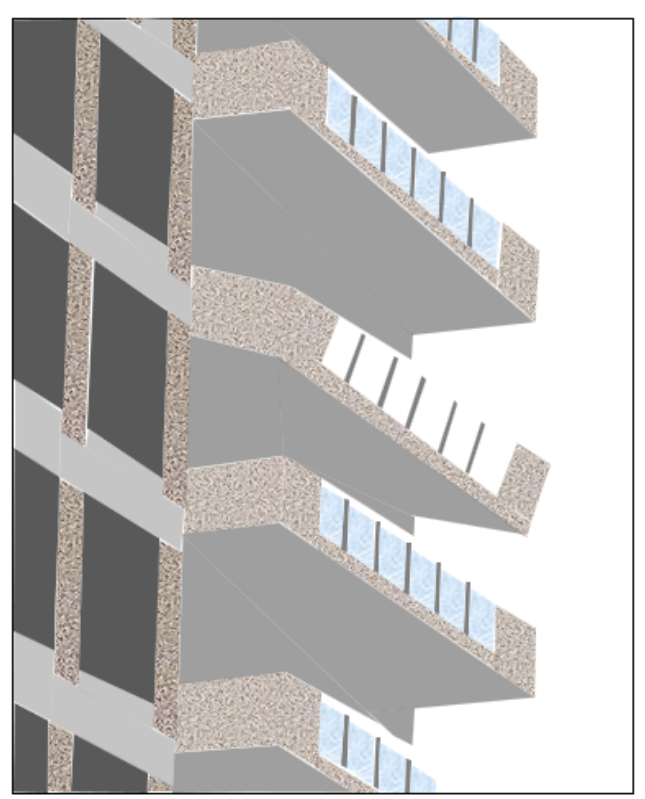

Figure 5: Inclined balcony slab [30].

Collapse of a reinforced concrete balcony slab [30]

A balcony of a fifteen years old building suddenly collapsed. The balcony structure severely cracked at the clamped end of the cantilevered slab, rotating approximately 17 degrees, but remained connected to the rest of the structure of the building, as is shown in Fig. 5.

The balcony floor structure is a reinforced concrete slab with $12 \mathrm{~cm}$ of thickness, $9.32 \mathrm{~m}$ long and $2.03 \mathrm{~m}$ wide (Fig. 6). The cantilevered slab is clamped in the outer edge of the living room slab, whose thickness is $15 \mathrm{~cm}$, and both are simply supported on the facade beam. The bottom of the two slabs are on the same level, so the difference in thickness between them results in a $3 \mathrm{~cm}$ step at the top of the cantilevered slab, located next to the beam (Fig. 7). 
The visual inspection of the fractured slab showed steel bars with $9.5 \mathrm{~mm}$ of diameter spaced $150 \mathrm{~mm}$. Analysis of samples of concrete and steel bars resulted in characteristic compressive strength $\left(\mathrm{f}_{\mathrm{ck}}\right)$ equal to $30 \mathrm{MPa}$ and yield stress of $500 \mathrm{MPa}$, respectively. The permanent vertical loads on the slab are concrete dead load $\left(3.0 \mathrm{kN} / \mathrm{m}^{2}\right)$, weight of the bottom coating $\left(0.4 \mathrm{kN} / \mathrm{m}^{2}\right)$, weight of the laying mortar $\left(1.0 \mathrm{kN} / \mathrm{m}^{2}\right)$ and weight of the marble floor $\left(0.56 \mathrm{kN} / \mathrm{m}^{2}\right)$. These loads generate a bending moment in the clamped section equal to $-10.55 \mathrm{kNm} / \mathrm{m}$. The flexural design considering only the permanent vertical loads and concrete with $\mathrm{f}_{\mathrm{ck}}$ of $14 \mathrm{MPa}$, value adopted in the building design, results in a steel area equal to $3.4 \mathrm{~cm} / \mathrm{m}$. This value is lower than the steel area actually utilized on the balcony slab, which is $4.72 \mathrm{~cm}^{2} / \mathrm{m}$.

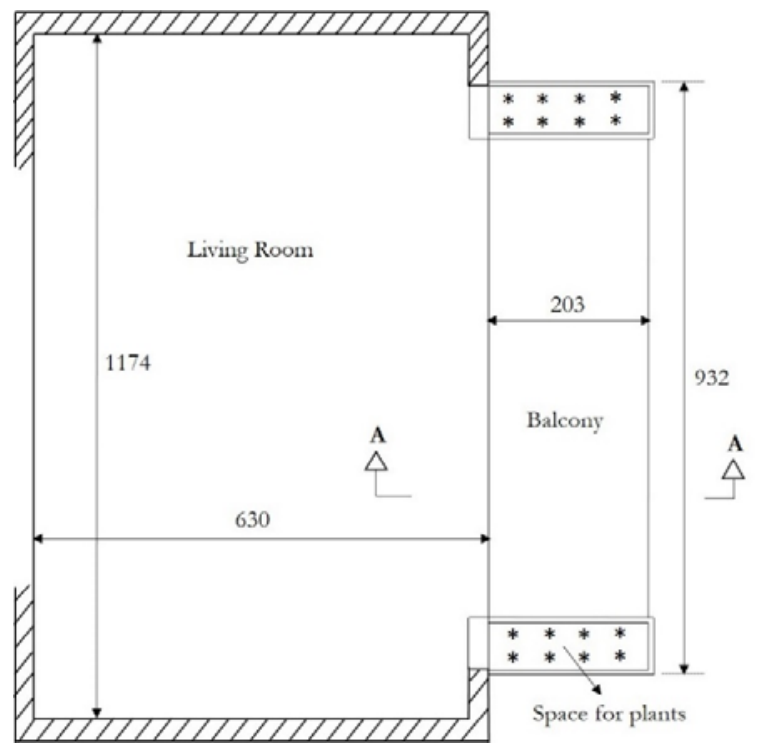

Figure 6: Dimensions of the living room and the balcony in $\mathrm{cm}$.

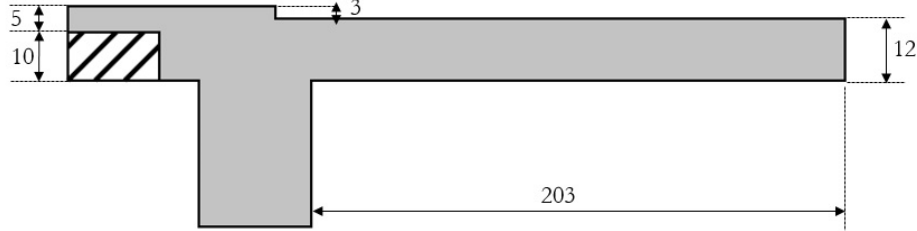

Figure 7: Cross-section A-A of the slabs (dimensions in $\mathrm{cm}$ ).

Thus, it was concluded that the accident was caused by the abrupt rectification of the steel bars of the negative reinforcement that were installed with double curvature in the form of a step, due to the rupture of the surface layer of concrete by the action of the straightened bars (Fig. 8).

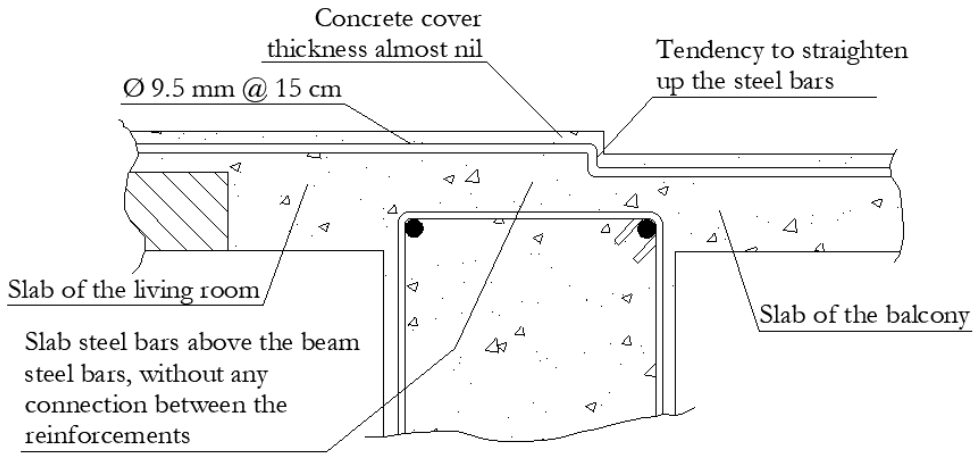

Figure 8: Detail of the steel bars before the accident [30].

\section{RESULTS}

\section{Bridge Concrete Arch [13]}

he arch was divided in eight finite elements, as shown in Fig. 4. Although a complete nonlinear analysis is possible [14-29], since the goal of this paper is to present a diagnosis of the analysed structure, a single measurement of the tested arch [13] is taken into account. Then, the procedure was carried out for the step of $10.15 \%$ of the collapse 
load i.e., experimental value of $6.902 \mathrm{kN}$, since the collapse load is $68 \mathrm{kN}$. The vertical displacement at the mid-span of the tested arch is equal to $4.43 \mathrm{~mm}$.

The LDM analysis reached applied load of $6.802 \mathrm{kN}$ (about $10 \%$ of the collapse load) and vertical displacement of $4.334 \mathrm{~mm}$ for the initial damage values in nodes $\mathrm{A}, \mathrm{B}, \mathrm{H}$ and $\mathrm{I}$ equal to $0.25,0.23,0.22$ and 0.12 , respectively. Compared to the experimental values, the absolute and relative displacement errors were equal to $0.096 \mathrm{~mm}$ and $2.16 \%$.

For the estimated initial damage values in the arch, it is possible to suggest minor repairs at nodes A, B, H and I, considering what is indicated by Flórez-López et al. [29] (Tab. 4), if the arch was not tested up to collapse and then returned to service.

$\begin{array}{cccc}\begin{array}{c}\text { Performance } \\ \text { level }\end{array} & \begin{array}{c}\text { Maximum expected } \\ \text { damage in beams }\end{array} & \begin{array}{c}\text { Maximum expected } \\ \text { damage in columns }\end{array} & \text { Description } \\ 1 & 0.30 & 0.10 & \text { The elements do not require any intervention after the event } \\ 2 & 0.40 & 0.30 & \text { Some minor repairs may be needed } \\ 3 & 0.50 & 0.40 & \text { The element requires reparation at reasonably costs } \\ 5 & 0.60 & 0.50 & \text { The structure requires a major rehabilitation process } \\ & & & \end{array}$

Table 4: Performance level for damage [29].

\section{Collapse of a reinforced concrete balcony slab [30]}

Since the acting permanent load is $4.96 \mathrm{kN} / \mathrm{m}^{2}$ during the accident, it was verified that the damage evolution law (Eqn. 14) that $G<Y(d)$, i.e. the loads did not cause the damage in the clamped section. This is corroborated by comparing the cracking moment $(15.73 \mathrm{kNm} / \mathrm{m})$ with the acting bending moment in the clamped section $(10.22 \mathrm{kNm} / \mathrm{m})$. To achieve the cracking moment $(15.73 \mathrm{kNm} / \mathrm{m})$ and the ultimate moment $(23.69 \mathrm{kNm} / \mathrm{m})$, the load in the balcony should be $7.63 \mathrm{kN} / \mathrm{m}^{2}$ and $11.5 \mathrm{kN} / \mathrm{m}^{2}$, respectively. Based on that and in the conditions observed in loco, the accident occurred due to the action of the straightened bars. In the ultimate condition of the slab section, was observed that the residual thickness was approximately $2 \mathrm{~cm}$, as shown in Fig. 9.

The simulation, considering large displacements, reached a damage value of 0.9995 and the horizontal and vertical displacement in the edge of the slab are equal to $13.57 \mathrm{~cm}$ and $58.99 \mathrm{~cm}$, respectively. These values lead to an angle approximately equal to $17.30^{\circ}$, which confirms the in loco observations. Note that the damage obtained in the analysis characterises an inacceptable structural behaviour [29] (Tab. 4), denoting that almost there is no cross section at the clamped end. Assuming that the damage penalises directly the inertia moment [27], the remaining thickness at the clamped end is estimated as $0.95 \mathrm{~cm}$, quite close to the field observations.

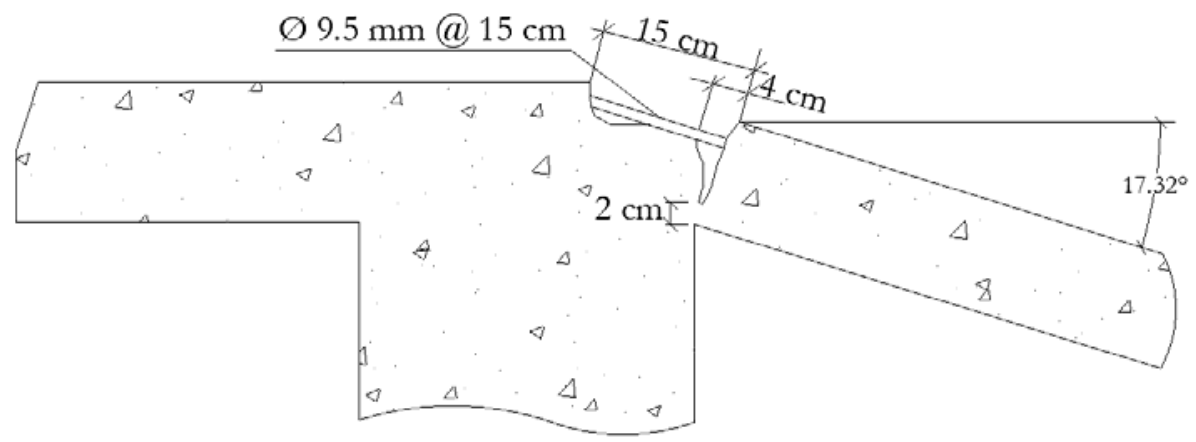

Figure 9: Geometry and typical reinforcement after the accident [25-26]. 


\section{CONCLUSION}

$\mathrm{T}$

his paper presents lumped damage mechanics $(\mathrm{LDM})$ as a diagnosis tool to evaluate damage levels (concrete cracking) in reinforced concrete (RC) structures. Differently from all previous studies, where LDM was used in nonlinear analyses, this paper showed that the LDM formulation can be easily applied in practical engineering problems. Therewith, LDM was applied as a diagnosis tool in two different structures: a former bridge arch in China that was tested in laboratory and a RC balcony slab in Brazil that collapsed after 15 years of service.

For the former bridge arch, LDM response was quite close to the experimental one and then initial damage values in four different points were estimate around 0.20 , concluding that minor repairs might be needed if the arch was returned to service.

On the other hand, the RC slab balcony collapsed with only permanent loads where, the reinforcement straightened up due to an incorrect design. By applying LDM, it was noticed that the analysis reached large displacements as the actual balcony, with a rotation near $17^{\circ}$, quite close to in loco observations. The calculated damage was 0.9995 , characterising collapse. Also, the residual thickness is estimated near to $1.0 \mathrm{~cm}$, quite close to in loco measure $(2.0 \mathrm{~cm})$.

Finally, regarding the analysed engineering problems in this paper, it is possible to observe that the LDM may be adequately a diagnosis tool to evaluate the levels of damage in structures, being able to determine the distribution of initial/current damage values and to verify its acceptability and safety for use. Moreover, it is feasible tool for technical analysis of actual structural accidents, such as the case of the RC balcony slab in Brazil.

\section{ACKNOWLEDGEMENTS}

7 he first author acknowledges CAPES for the financial support of his D.Sc. studies. The second author acknowledges PNPD/CAPES for the financial support of her Postdoc studies.

\section{APPENDIX}

T ust for convenience, the flexibility matrix of a damaged member (12) is reproduced here:

$$
[\mathbf{F}(\mathbf{D})]_{b}=\left[\begin{array}{ccc}
\frac{1}{1-d_{i}} F_{11}^{0} & F_{12}^{0} & F_{13}^{0} \\
F_{12}^{0} & \frac{1}{1-d_{j}} F_{22}^{0} & F_{23}^{0} \\
F_{13}^{0} & F_{23}^{0} & F_{33}^{0}
\end{array}\right]
$$

For frame members such matrix is denoted as:

$$
[\mathbf{F}(\mathbf{D})]_{b}=\left[\begin{array}{ccc}
\frac{1}{1-d_{i}} \frac{L_{b}}{3 E I} & -\frac{L_{b}}{6 E I} & 0 \\
-\frac{L_{b}}{6 E I} & \frac{1}{1-d_{j}} \frac{L_{b}}{3 E I} & 0 \\
0 & 0 & \frac{L_{b}}{A E}
\end{array}\right]
$$

For arch elements the terms of the flexibility matrix are given by: 


$$
\begin{aligned}
& F_{11}^{0}=\frac{1}{2} \frac{R_{b}\left(-4 \sin \chi_{b}+3 \chi_{b}-2 \chi_{b} \cos ^{2} \chi_{b}+3 \sin \chi_{b} \cos \chi_{b}\right)}{E I \sin ^{2} \chi_{b}}-\frac{1}{2} \frac{\sin \chi_{b} \cos \chi_{b}-\chi_{b}}{R_{b} A E \sin ^{2} \chi_{b}} \\
& F_{12}^{0}=\frac{1}{2} \frac{R_{b}\left(-2 \sin \chi_{b}+\chi_{b}+\sin \chi_{b} \cos \chi_{b}\right)}{E I \sin ^{2} \chi_{b}}-\frac{1}{2} \frac{\sin \chi_{b} \cos \chi_{b}-\chi_{b}}{R_{b} A E \sin ^{2} \chi_{b}} \\
& F_{13}^{0}=\frac{1}{2} \frac{R_{b}^{2}\left(-5 \sin \chi_{b}+5 \chi_{b} \cos \chi_{b}-\chi_{b} \cos \chi_{b}-3 \chi_{b}-2 \chi_{b} \cos ^{2} \chi_{b}\right)}{E I \sin ^{2} \chi_{b}} \\
& -\frac{1}{2} \frac{-\chi_{b}-\sin \chi_{b}+\sin \chi_{b} \cos \chi_{b}+\chi_{b} \cos \chi_{b}}{A E \sin ^{2} \chi_{b}} \\
& F_{22}^{0}=\frac{1}{2} \frac{R_{b}\left(\chi_{b}-\sin \chi_{b} \cos \chi_{b}\right)}{E I \sin ^{2} \chi_{b}}-\frac{1}{2} \frac{\sin \chi_{b} \cos \chi_{b}-\chi_{b}}{R_{b} A E \sin ^{2} \chi_{b}} \\
& F_{23}^{0}=\frac{1}{2} \frac{R_{b}^{2}\left(-\sin \chi_{b}-\chi_{b} \cos \chi_{b}+\chi_{b}+\sin \chi_{b} \cos \chi_{b}\right)}{E I \sin ^{2} \chi_{b}} \\
& -\frac{1}{2} \frac{-\chi_{b}-\sin \chi_{b}+\sin \chi_{b} \cos \chi_{b}+\chi_{b} \cos \chi_{b}}{A E \sin ^{2} \chi_{b}} \\
& F_{33}^{0}=\frac{R_{b}^{3}\left(-3 \sin \chi_{b}-\chi_{b} \cos ^{2} \chi_{b}-\chi_{b} \cos \chi_{b}+2 \chi_{b}+3 \sin \chi_{b} \cos \chi_{b}\right)}{E I \sin ^{2} \chi_{b}} \\
& -\frac{R_{b}\left(-\chi_{b}-\sin \chi_{b}+\sin \chi_{b} \cos \chi_{b}+\chi_{b} \cos \chi_{b}\right)}{A E \sin ^{2} \chi_{b}}
\end{aligned}
$$

\section{REFERENCES}

[1] Rehman, S.K.U., Ibrahim, Z., Memom, S.A. and Jameel, M. (2016). Nondestructive test methods for concrete bridges: a review, Constr. Build. Mater., 107, pp. 58-86. DOI: 10.1016/j.conbuildmat.2015.12.011.

[2] Noorsuhada, M.N. (2016). An overview on fatigue damage assessment of reinforced concrete structures with the aid of acoustic emission technique, Constr. Build. Mater., 112, pp. 424-439. DOI: 10.1016/j.conbuildmat.2016.02.206.

[3] Solla, M., Lorenzo, H., Novo, A. and Caamaño, J. (2012). Structural analysis of the Roman Bibei bridge (Spain) based on GPR data and numerical modelling, Automat. Constr., 22, pp. 334-339. DOI: 10.1016/j.autcon.2011.09.010.

[4] Ruggiero, A., Bonora, N., Curiale, G., De Muro, S., Iannitti, G., Marfia, S., Sacco, E., Scafati, S. and Testa, G. (2019). Full scale experimental tests and numerical model validation of reinforced concrete slab subjected to direct contact explosion, Int. J. Impact Eng., 132, pp. 103309. DOI: 10.1016/j.ijimpeng.2019.05.023.

[5] Jesus, A.M.P. de., Silva, A.L.L. da., Figueiredo, M. V., Correia, J.A.F.O., Ribeiro, A.S. and Fernandes, A.A. (2011). Strain-life and crack propagation fatigue data from several Portuguese old metallic riveted bridges, Eng. Fail. Anal., 18(1), pp. 148-163. DOI: 10.1016/j.engfailanal.2010.08.016.

[6] Liu, Z., Correia, J., Carvalho, H., Mourão, A., Jesus, A., Calçada, R. and Berto, F. (2019). Global-local fatigue assessment of an ancient riveted metallic bridge based on submodelling of the critical detail, Fatigue Fract. Eng. Mater. Struct., 42(2), pp. 546-560. DOI: 10.1111/ffe.12930.

[7] Masciotta, M.G., Pellegrini, D., Brigante, D., Barontini, A., Lourenço, P.B., Girardi, M., Padovani, C. and Fabbrocino, G. (2019). Dynamic characterization of progressively damaged segmental masonry arches with one settled support: experimental and numerical analyses, Frat. Ed Integrità Strutt., 14(51), pp. 423-441. DOI: 10.3221/IGF-ESIS.51.31.

[8] Vásques, J.A., Junemann, R., de la Llera, J.C., M.Eeri, Hube, M.A., M.Eeri, and Chacón, M.F. (2020). Three-dimensional nonlinear response history analyses for earthquake damage assessment: A reinforced concrete wall building case study. Earthq. Spectra, 37(1), pp. 235-261. DOI: 10.1177/8755293020944180.

[9] Ukrainczyk, N., Ukrainczyk, V. (2008). A neural network method for analysing concrete durability, Mag. Concr. Res., 60(7), pp. 475-486, DOI: 10.1680/macr.2007.00016. 
[10] Wu, J., Zhou, Y.M., Zhang, R., Liu, C.B. and Zhang, Z.C. (2020). Numerical simulation of reinforced concrete slab subjected to blast loading and the structural damage assessment, Eng. Fail. Anal., 118, pp. 104926.

DOI: $10.1016 /$ j.engfailanal.2020.104926.

[11] Abedeni, M. and Zhang, C.W. (2021). Dynamic vulnerability assessment and damage prediction of RC columns subjected to severe impulsive loading, Struct. Eng. Mech., 77(4), pp. 441-461. DOI: 10.12989/sem.2021.77.4.441.

[12] Tenorio-Monteiro, E. and Juárez-Luna, G. (2021). Beam-column finite element with embedded discontinuities for modelling damage in reinforced concrete prismatic elements, Structures, 29, pp. 1934-1953.

DOI: $10.1016 /$ j.istruc.2020.12.055.

[13] Tang, X.S., Zhang, J.R., Li, C.X., Xu, F.H. and Pan, J. (2005). Damage analysis and numerical simulation for failure process of a reinforced concrete arch structure, Comput. Struct., 83, pp. 2609-2631. DOI: 10.1016/j.compstruc.2005.03.017.

[14] Ooi, E.T., Yang, Z.J. (2011). Modelling crack propagation in reinforced concrete using a hybrid finite element-scaled boundary finite element method, Eng. Fract. Mech., 78(2), pp. 252-73, Doi: 10.1016/j.engfracmech.2010.08.002.

[15] Bakir, P.G., Erdogan, Y.S. (2013). Damage identification in reinforced concrete beams by finite element model updating using parallel and hybrid genetic algorithms, Int. J. Comput. Methods, 10(03), pp. 1350010, DOI: $10.1142 / \mathrm{S} 0219876213500102$.

[16] Shardakov, I.N., Shestakov, A.P., Glot, I.O., Bykov, A.A. (2016). Process of cracking in reinforced concrete beams (simulation and experiment), Frat. Ed Integrità Strutt., 10(38), pp. 339-50, DOI: 10.3221/IGF-ESIS.38.44.

[17] Alañón, A., Cerro-Prada, E., Vázquez-Gallo, M.J., Santos, A.P. (2018). Mesh size effect on finite-element modeling of blast-loaded reinforced concrete slab, Eng. Comput., 34(4), pp. 649-58, DOI: 10.1007/s00366-017-0564-4.

[18] Flórez-López J. (1993) Modelos de daño concentrado para la simulación del colapso de pórticos planos, Rev. Int. Mét. Num. Cálc. Dis. Ing., 9(2), pp. 123-139.

[19] Cipollina, A., López-Inojosa, A. and Flórez-López, J. (1995). A simplified damage mechanics approach to nonlinear analysis of frames, Comput. Struct., 54(6), pp. 1113-26. DOI: 10.1016/0045-7949(94)00394-I.

[20] Perdomo, M.E., Ramírez, A. and Flórez-López, J. (1999). Simulation of damage in RC frames with variable axial forces, Earthq. Eng. Struct. Dyn., 28(3), pp. 311-28. DOI: 10.1002/(sici)1096-9845(199903)28:3<311::aid-eqe819>3.0.co;2-d.

[21] Rajasankar, J., Iyer, N.R. and Prasad, A.P. (2009). Modelling inelastic hinges using CDM for nonlinear analysis of reinforced concrete frame structures. Comput. Concr.,6(4), pp. 319-41. DOI: 10.12989/cac.2009.6.4.319.

[22] Teles, D.V.C., Cunha, R.N., Amorim, D.L.N.F, Picón, R. and López, J.F. (2021). Parametric study of dynamic behaviour of RC dual system design with the Brazilian Standard Code using the lumped damage model, J. Brazilian Soc. Mech. Sci. Eng., 43(5), pp. 246. DOI: 10.1007/s40430-021-02977-8.

[23] Yang, T. -S. and Wang, J. -L. (2010). Damage analysis of three-dimensional frame structure suffering from impact, J. Vib. Shock, 29(12), pp. 177-180.

[24] Teles, D.V.C., Oliveira, M.C. and Amorim, D.L.N.F. (2020). A simplified lumped damage model for reinforced concrete beams under impact loads, Eng. Struct., 205. DOI: 10.1016/j.engstruct.2019.110070.

[25] Oliveira, M.C., Teles, D.V.C. and Amorim, D.L.N.F. (2020). Shear behaviour of reinforced concrete beams under impact loads by the Lumped Damage framework, Frat. ed Integrita Strutt., 53, pp. 13-25. DOI: 10.3221/IGF-ESIS.53.02.

[26] Amorim, D.L.N.F., Proença, S.P.B. and Flórez-López, J. (2013). A model of fracture in reinforced concrete arches based on lumped damage mechanics, Int. J. Solids Struct., 50(24), pp. 4070-4079. DOI: 10.1016/j.ijsolstr.2013.08.012.

[27] Amorim, D.L.N.F., Proença, S.P.B. and Flórez-López, J. (2014). Simplified modeling of cracking in concrete: Application in tunnel linings, Eng. Struct., 70, pp. 23-35. DOI: 10.1016/j.engstruct.2014.03.031.

[28] Brito, T.I.J., Santos, D.M., Santos, F.A.S., Cunha, R.N. and Amorim, D.L.N.F. (2020). On the lumped damage modelling of reinforced concrete beams and arches, Frat. ed Integrita Strutt., 54, pp. 1-20. DOI: 10.3221/IGF-ESIS.54.01.

[29] Flórez-López, J., Marante, M.E., Picón, R. (2015). Fracture and damage mechanics for structural engineering of frames: State-of-the-art industrial applications, Engineering Science Reference. ISBN: 978-1466663794.

[30] Lima, N.A. (1996). Empuxo no vazio provoca o colapso da estrutura de uma varanda, In: Acidentes Estruturais na Construção Civil, São Paulo, PINI, 1, pp. 149-154. ISBN: 978-8572660617. 